\title{
Eventos del deseo. Sexualidades minoritarias en las culturas/ literaturas de España y Latinoamérica a finales del siglo XX
}

Dieter Ingenschay (ed.)

Madrid y Frankfurt, Iberoamericana-Vervuert, 2018, 268 pp. ISBN: 978-

84-16922-71-0

Este volumen, editado por Dieter Ingenschay, ha seguido la genealogía habitual de muchas antologías críticas especializadas. Como consigna el propio responsable de la edición, el origen del libro se remonta a un encuentro que reunió, en 2014, a una veintena de investigadorxs provenientes de instituciones de diversas partes del mundo, para debatir a propósito de las sexualidades minoritarias en el ámbito español y latinoamericano más reciente. Buena parte de los textos aquí recogidos provienen de ese foro, a los que se han sumado nuevos artículos, a fin de conformar la enjundiosa compilación de estos Eventos del deseo.

Entre el encuentro académico en Berlín y la publicación, Pedro Lemebel fallecería. Referente indiscutible para el ámbito temático y vital del que se ocupan los artículos del libro, es este artista chileno, junto al ya también desaparecido Néstor Perlongher, el dúo autoral más citado, lo que no hace otra cosa que confirmar su peso en el panorama de los estudios literarios y culturales centrados en las sexualidades/textualidades no hegemónicas. En un gesto, por ello, que recoge además un hermoso vínculo de amistad personal, Ingenschay dedica el libro a la memoria de Pedro. Un evento del deseo, sito en el paratexto, que no quiero pasar por alto.

Uno de los mayores aciertos de la publicación reside en la elección del título. Entre la realidad y el deseo - título cernudiano para una diatriba encarnada (a veces encarnizada) que nos viene a medida - algo acontece, sucede, va siendo. Son estos eventos, que implican una salida, una emergencia que, en la fórmula elegida, no requiere ni siquiera forzosamente de una agentividad explícita, sino que le basta con dar testimonio palpable de la imposibilidad de que este deseo se vele, se amordace, se borre o se invisibilice. Emergerá por su misma urgente imposición constitutiva. Imbricado, en cualquier caso, en una dimensión colectiva, con toda probabilidad en consonancia con la noción de comunidad sobre la que reflexiona encomiablemente Marta Segarra en su texto - esto es, con la articulación de lo impropio y llevando al sujeto fuera de sí-, el deseo cobra una dimensión política, señala ostentosamente otro modo de ser que, en su proceso de normalización, en la paulatina y necesaria conquista de derechos, que ha transitado en el periodo delimitado y sigue en la actualidad, se debate entre cómo mantener una voluntad crítica radical a la vez que se institucionaliza. Esta tensión cruza por entero el volumen y en ella reside uno de los motores más potentes de su propuesta teóricocrítica. 
Escrito a modo de estudio introductorio, el brillante texto de Brad Epps consigue recoger esta articulación conjunta alrededor de la forma del neologismo que inventa: fráxito, "con el cual se pretende designar menos una síntesis de fracaso y éxito que una tensa y oscilante hibridación bastarda" que nos llevaría a la pregunta que comparten "muchos de los artículos aquí incluidos: ¿cómo puede el impulso alternativo LGBT y/o queer retener - o recuperar - su energía crítica ante su propio éxito?" (11). Epps consigue trenzar las distintas aportaciones que constituyen el volumen, ponerlas en diálogo y proponer por y con ellas una cartografía de actuación política y crítica. No es el único; Rafael M. Mérida Jiménez presenta una muestra del valioso trabajo que viene realizando, con el rigor que lo caracteriza, revisando los textos auto(bio)gráficos de mujeres trans - en sentido amplio- que han vivido la dictadura y la transición españolas, para los que reclama mayor atención crítica. Ingenschay nos ofrece un documentado estudio comparativo entre las dictaduras de España, Argentina y Chile, muestra la diferencia entre los tres modelos y cómo de determinados sistemas de represión surgen subversiones y emancipaciones derivadas, acompañadas de modelos legislativos concretos. Igual de excelente en el manejo de una perspectiva panorámica es el artículo de Zurian, centrado en las series televisivas. Incómoda y trastocadora me ha parecido la aportación de Nina Lawrenz y Martha Zapata Galindo, que canaliza una pertinente crítica al neoliberalismo y a las exclusiones que este genera y reproduce en lo excluido. Por su parte, Janet Reinstädler propone una inflexión erótica literaria, que a modo de boom rompiera con las enconadas censuras y represiones del franquismo, desde 1977 hasta inicios del XXI. Un excelente termómetro para su hipótesis lo constituye la colección "La Sonrisa Vertical".

Precisamente en ella se centra la emocionante y concienzuda labor detectivesca de Estrella Díaz Fernández, que termina elaborando una teoría sostenida y plausible de quién se esconde detrás de la firma Irene González Frei. Esa misma línea de excelencia en lo que se refiere a documentación, genealogía y propuesta teórica es compartida por todos los textos que, en el volumen, eligen una perspectiva más cerrada sobre un corpus concreto. Las lecturas son, en todos los casos, iluminadoras. Así, la recuperación-reivindicación de Jorge Luis Peralta de un poco atendido Óscar Hermes Villordo; el análisis de José Luis Ramos Rebollo del inolvidable personaje de Nazario, Anarcoma, y su confección intertextual en la década de los ochenta; el estudio de Bernhard Chappuzeau sobre la figura del argentino Edgardo Cozarinsky; la sagaz apuesta interpretativa que propone Guadalupe Marei para la potente trilogía con la que Gabriela Cabezón Cámara ha cincelado su ingreso en la literatura, o el no menos excelente y profusamente documentado estudio de Fernando A. Blanco de la producción cultural chilena porno activista más reciente, con el Colectivo de Disidencia Sexual (CUDS) y José Carlos Henríquez (Camilo). 
Motivo de celebración es que haya un espacio para las aportaciones indígenas, de la mano de Elena Madrigal, así como la consideración de una de las literaturas más marginadas entre las marginadas: la literatura infantil, gracias a la contribución de Alfredo Martínez-Expósito. El ya mencionado artículo de Marta Segarra constituye un justo reconocimiento a Maria-Mercè Marçal por sus propuestas poéticas y políticas. Y, para cerrar este repaso dolorosamente somero por lo que son textos muy ricos en matices y generosos en sugerencias metodológicas y nociones teóricas, no quiero dejar de mencionar la brillante lectura que nos regala Alberto Mira de dos infancias góticas, dos modelos distintos, que pueden compartir sin embargo esa idea del fracaso-exitoso que supone ese crecer torcido.

MERI TORRAS

meri.torras@uab.cat

\section{Foreign Women Authors under Fascism and Francoism: Gender, Translation and Censorship}

Pilar Godayol y Annarita Taronna (eds.)

Newcastle upon Tyne, Cambridge Scholars Publishing, 2018, 217 pp.

ISBN: 978-15-2750-665-7

Pilar Godayol e Annarita Taronna ofrécennos un volume dividido en dúas partes asentado na tríade censura-tradución-xénero que nos amosa de que maneira os sistemas totalitarios de Mussolini e Franco se esforzaron por impedir, manipular e condicionar a entrada de literatura estranxeira de autoría feminina considerada subversiva.

Os catro primeiros capítulos do volume abordan realidades integradas no contexto do fascismo italiano. Ata 1934 non existiu en Italia unha censura preventiva, mais os libros podían ser secuestrados após seren publicados. A noción de tradución concibíase daquela como un medio para estender o proceso de estandarización, polo que as traducións eran en realidade adaptacións.

No primeiro destes capítulos, da autoría de Valerio Ferme, achéganse os motivos que suscitaron o interese do mercado literario italiano polas autorías femininas estadounidenses no contexto da etapa fascista, atribuíndoo a unha mitificación de Estados Unidos pola sociedade italiana e establecendo como conclusión que as obras que escaparon da censura, que adoitaban ser localizadas, censuradas e recortadas, eran empregadas para domesticar as mulleres cara ao terreo privado. 